\title{
Octamethyl-octaundecylcyclo[8]pyrrole: A Promising Sulfate Anion Extractant
}

\author{
Leah R. Eller, Marcin Stępień, Christopher J. Fowler, Jeong Tae Lee, \\ Jonathan L. Sessler*, Bruce A. Moyer*
}

\section{Supporting Information}

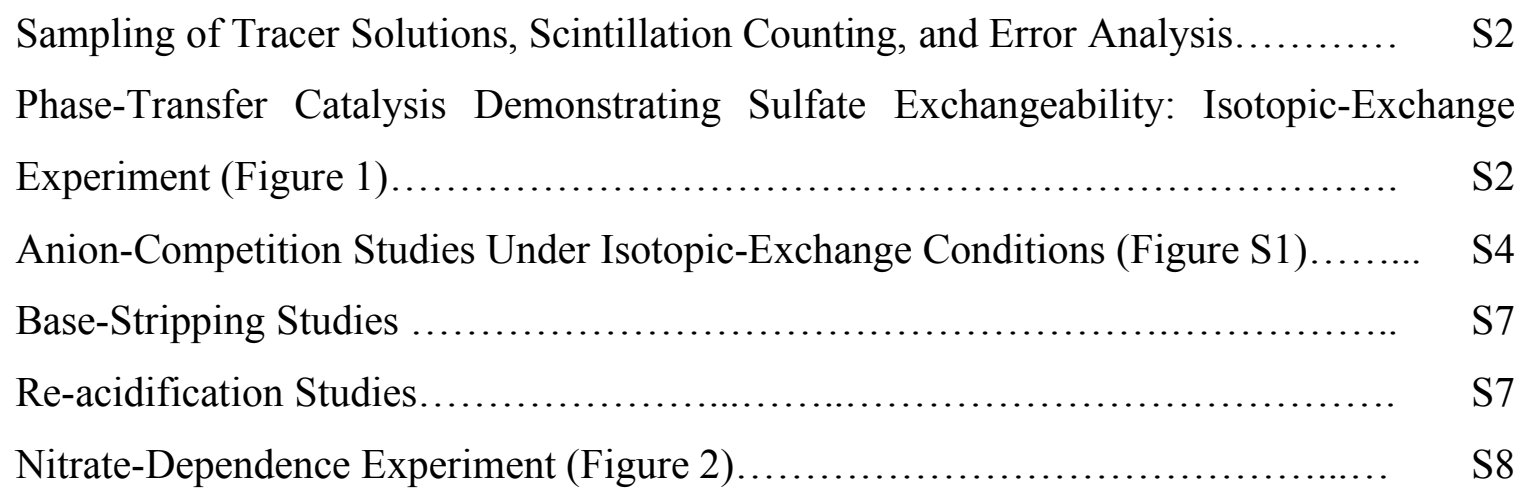




\section{Sampling of Tracer Solutions, Scintillation Counting, and Error Analysis}

After being removed from the rotating mixer, sample vials were centrifuged for 10 minutes at $3000 \mathrm{rpm}$ to separate the liquid phases. They were transferred back to the radiological hood for final analysis. Respective aliquots of $0.1 \mathrm{~mL}$ and $0.3 \mathrm{~mL}$ of each aqueous and organic phase were transferred to individual scintillation vials each already containing $15 \mathrm{~mL}$ of Ultima Gold scintillation cocktail. These scintillation vials were then placed on a beta counter (Packard TriCarb ${ }^{\circledR}$ Model 2700TR) to measure the radioactivity in each phase. Raw data were worked up using the spreadsheet program Excel, which allowed the apparent distribution values, $D_{\mathrm{SO} 4}$ (experimentally defined as $\left.\left[{ }^{35} \mathrm{SO}_{4}{ }^{2-}\right]_{\text {org }} /\left[{ }^{35} \mathrm{SO}_{4}{ }^{2-}\right]_{\mathrm{aq}}\right)$, to be calculated. The limit of detection was set at a count rate 3 times the background count rate, corresponding to $D_{\text {SO4 }}$ values of approximately $1 \times 10^{-4}$. Quenching was usually absent but was no worse than approximately 60\%. Count times varied up to 30 minutes, sufficient in almost all cases to give more than 10,000 counts, making the counting statistics a relatively small source of experimental error. Overall, precision error is considered to be $\pm 10 \%$, consisting of volumetric sampling error, temperature fluctuations (temperature variation of $D_{\mathrm{SO} 4}$ itself during equilibration, in addition to density changes of solutions on handling under ambient conditions), and volatility of toluene. Systematic error due to kinetics and adsorption artifacts presents additional issues, as discussed below and in the published text. The reader should note that the distinction between the apparent $D_{\mathrm{SO} 4}$ and actual $D_{\mathrm{SO} 4}$, defined as $\left[\mathrm{SO}_{4}{ }^{2-}\right]_{\mathrm{org}} /\left[\mathrm{SO}_{4}{ }^{2-}\right]_{\mathrm{aq}}$, is only relevant for non-equilibrium experiments (e.g., the isotopicexchange experiment in Fig. 1) in which the tracer is added to the aqueous phase and cyclo[8]pyrrole $\mathbf{1}$ is in the form of the organic-phase sulfate salt $[\mathbf{1} \cdot 2 \mathrm{H}]^{2+} \cdot \mathrm{SO}_{4}{ }^{2-}$.

\section{Phase-Transfer Catalysis Demonstrating Sulfate Exchangeability: Isotopic Exchange (Figure 1)}

Three sets of experiments were conducted involving: (1) the phase-transfer catalyzed system, $[\mathbf{1} \cdot 2 \mathrm{H}]^{2+} \cdot \mathrm{SO}_{4}{ }^{2-}$ with $\mathrm{A} 336 \mathrm{~N}$; (2) the noncatalyzed control, $[1 \cdot 2 \mathrm{H}]^{2+} \cdot \mathrm{SO}_{4}{ }^{2-}$ used alone; and (3) the phase-transfer catalyst control, A336N used alone. The following procedure was employed, with some additional variation for the $A 336 \mathrm{~N}$ control as described later. Equilibration experiments were conducted in $2.0 \mathrm{~mL}$ 
polypropylene centrifuge tubes placed into $50 \mathrm{~mL}$ conical vials as secondary containment. For the Aliquat 336-nitrate $(\mathrm{A} 336 \mathrm{~N})$ controls, $0.5 \mathrm{~mL}$ of a toluene solution containing $0.1 \mathrm{mM}$ A336N was placed into each centrifuge tube. For the cyclo[8]pyrrole controls, $0.5 \mathrm{~mL}$ of a toluene solution containing $0.5 \mathrm{mM}$ cyclo[8]pyrrole sulfate $[1 \cdot 2 \mathrm{H}]^{2+} \cdot \mathrm{SO}_{4}{ }^{2-}$ was placed into each centrifuge tube. A third set of tubes contained 0.5 $\mathrm{mL}$ of a toluene solution that was $0.1 \mathrm{mM}$ in $\mathrm{A} 336 \mathrm{~N}$ and $0.5 \mathrm{mM}$ in $[\mathbf{1} \cdot 2 \mathrm{H}]^{2+} \cdot \mathrm{SO}_{4}{ }^{2-}$.

The centrifuge tubes containing the organic phases were transferred to a separate hood in a radiological area for addition of the radioactive sulfur-35 tracer. (CAUTION: The experiment involves radioactive material and should therefore be used in approved facilities; personnel should be appropriately trained to minimize personal exposure, control contamination, and dispose of wastes properly.) This tracer was in the form of an aqueous solution consisting of $0.5 \mathrm{mM} \mathrm{Na}_{2} \mathrm{SO}_{4}$ spiked with $\mathrm{Na}_{2}{ }^{35} \mathrm{SO}_{4}$. A $0.5 \mathrm{~mL}$ aliquot of the aqueous tracer solution was added to each centrifuge tube prepared above by automatic pipette to give a 1:1 phase volume ratio (organic:aqueous, $\mathrm{O} / \mathrm{A}$ ). The activity of the aqueous phase prior to equilibration was approximately $0.5 \mu \mathrm{Ci} / \mathrm{mL}$. The centrifuge tubes were then collected into larger, $50 \mathrm{~mL}$ conical vials (approximately four tubes per vial) to provide for secondary containment. After checking for radioactive contamination on the surfaces of the vials, the samples were removed from the radiological area and were placed on a rotating mixer in a temperature-controlled airbox at $25{ }^{\circ} \mathrm{C}$. Samples were removed from the rotating mixer at designated time points over a period of up to $72 \mathrm{hrs}$ as shown in Fig. 1.

Excellent reproducibility was observed for the phase-transfer catalyzed system, $[\mathbf{1} \cdot 2 \mathrm{H}]^{2+} \cdot \mathrm{SO}_{4}{ }^{2-}$ with $\mathrm{A} 336 \mathrm{~N}$, and the noncatalyzed control, $[\mathbf{1} \cdot 2 \mathrm{H}]^{2+} \cdot \mathrm{SO}_{4}{ }^{2-}$ used alone. The data shown in Fig. 1 were taken from at least three different experiments for each data set. As shown, a single trend with minimal scatter was obtained in each case. However, less reproducibility was obtained with the phase-transfer catalyst control, A336N used alone at $0.1 \mathrm{mM}$. In this case, evidence pointed to interfacial anomalies that would be expected for a surfactant at low concentration. For example, equilibrations in glass vials gave sharply decreasing $D_{\mathrm{SO} 4}$ values with time, even going below the detection limit, whereas equilibrations in Teflon and polypropylene vials did not show such sharply deviant behavior. Accordingly, points taken using glass vials were 
eliminated. The material used for the vial lids also led to differences in behavior, and we eliminated points obtained when foil inserts were used, owing to sharply decreasing $D_{\text {SO4 }}$ values with time. The data shown for the A336N control in Fig. 1 were taken from five separate experiments, using $0.5-1 \mathrm{~mL}$ phase volumes and two kinds of polypropylene centrifuge tubes in the phase contacting. Even so, the data for times greater than $10 \mathrm{~h}$ still showed evidence for decreasing $D_{\mathrm{SO} 4}$ values. Because no time dependence whatsoever is expected beyond a few minutes of phase contacting for A336N, we take the average $D_{\text {SO4 }}$ value of the $1-4 \mathrm{~h}$ measurements to be $0.0021 \pm 0.0006$.

\section{Anion Competition Studies Under Isotopic-Exchange Conditions (Figure S1)}

In order to test further the utility of cyclo[8]pyrrole $\mathbf{1}$ as a potential extractant, attempts were made to test whether other anions could be exchanged for sulfate using the above protocol for the isotope-exchange experiment shown in Fig. 1. Accordingly, toluene solutions of $[1 \cdot 2 \mathrm{H}]^{2+} \cdot \mathrm{SO}_{4}{ }^{2-}(0.5 \mathrm{mM})$ and $0.1 \mathrm{mM} \mathrm{A} 336 \mathrm{~N}$ were treated with aqueous solutions containing $0.5 \mathrm{mM} \mathrm{Na}_{2} \mathrm{SO}_{4}$ and $0.1-100 \mathrm{mM} \mathrm{NaX}\left(\mathrm{X}=\mathrm{Cl}, \mathrm{Br}, \mathrm{I}, \mathrm{NO}_{3}\right)$ for $4 \mathrm{~h}$. Under these conditions, $D_{\mathrm{SO} 4}$ values of 1 would be expected in the absence of competition, with smaller values indicating an increased displacement of sulfate from the protonated cyclo[8]pyrrole receptor in the organic phase. While in all cases, the greatest decreases in $D_{\text {SO4 }}$ values were observed with the least hydrophilic anions, as would be expected according to the Hofmeister bias, a detailed analysis of the data revealed that equilibrium was not being reached under these conditions. The experimental procedure and results are described below.

Anion-exchange equilibration experiments were conducted in $2.0 \mathrm{~mL}$ polypropylene centrifuge tubes placed into $50 \mathrm{~mL}$ conical vials as secondary containment. To each centrifuge tube was added a toluene solution containing $0.5 \mathrm{mM}$ $[1 \cdot 2 \mathrm{H}]^{2+} \cdot \mathrm{SO}_{4}{ }^{2-}$ and $0.1 \mathrm{mM} \mathrm{A} 336 \mathrm{~N}$. Control tubes contained toluene solutions of 0.1 mM A336N alone.

The centrifuge tubes containing the organic phases were transferred to a separate hood in a radiological area for addition of the same sulfur-35 tracer used in the sulfate equilibration studies detailed above. A $0.5 \mathrm{~mL}$ aliquot of the spiked tracer solution was added to each centrifuge tube by automatic pipette to give a 1:1 $\mathrm{O} / \mathrm{A}$ ratio. The aqueous 
solution consisted of $0.5 \mathrm{mM} \mathrm{Na}_{2} \mathrm{SO}_{4}$ and $0.1 \mathrm{mM}, 1.0 \mathrm{mM}$, or $100 \mathrm{mM} \mathrm{NaCl}, \mathrm{NaBr}$, $\mathrm{NaI}$, or $\mathrm{NaNO}_{3}$, respectively, spiked with $\mathrm{Na}_{2}{ }^{35} \mathrm{SO}_{4}$. The activity of the aqueous phase prior to equilibration was approximately $0.5 \mu \mathrm{Ci} / \mathrm{mL}$. These centrifuge tubes were collected into larger, $50 \mathrm{~mL}$ conical vials (approximately 4 tubes per vial) as secondary containment. After checking for radioactive contamination on the surfaces of the vials, the samples were removed from the radiological area and were placed on a rotating mixer in a temperature-controlled airbox $\left(t=4 \mathrm{hr}, \mathrm{O} / \mathrm{A}=1,25^{\circ} \mathrm{C}\right)$. Sampling and radiometric analysis was carried out as described above.

The results obtained for toluene solutions containing $0.5 \mathrm{mM}[\mathbf{1} \cdot 2 \mathrm{H}]^{2+} \cdot \mathrm{SO}_{4}{ }^{2-}$ and $0.1 \mathrm{mM} \mathrm{A336N}$ are shown in Figure S1(a), whereas those for A336N alone (also 0.1 $\mathrm{mM}$ ) are shown in Figure S1(b). The control shows little ability of the quaternary ammonium phase-transfer catalyst to extract sulfate without the anion receptor (Fig. $\mathrm{S} 1(\mathrm{~b})$ ). As expected from the Hofmeister bias, the suppression of $D_{\mathrm{SO} 4}$ grows worse as the hydration of the competing anion decreases. The phase-transfer catalyzed system (Fig. S1(a)) gives rise to data that are consistent with this same trend, but which are the result of kinetic rather than an equilibrium factors. Support for the conclusion that the competition experiments shown in Figure S1(a) are not reflecting complete equilibrium exchange comes from an appreciation of the fact that when the aqueous phase is at 0.1 $\mathrm{mM}$ competing anion, the $D_{\mathrm{SO} 4}$ value can be no smaller than 0.818 . This is because, under these conditions, there is insufficient aqueous nitrate to displace more than $10 \%$ of the sulfate from the organic phase. The minimum $D_{\mathrm{SO} 4}$ value is $(0.5-0.05) /(0.5+0.05)=$ 0.818 . Here, the 0.05 figure comes from $(0.1) / 2$, reflecting the fact that the aqueous nitrate concentration is $0.1 \mathrm{mM}$ and that the charge on nitrate anion is half that of sulfate anion at near-neutral $\mathrm{pH}$. In other words, were the full quantity of nitrate anion to get extracted into the organic phase, it would serve to displace $0.05 \mathrm{mM}$ sulfate into the aqueous phase. Because all $D_{\mathrm{SO} 4}$ values are smaller than 0.818 , and indeed much smaller for nitrate and iodide, it is concluded that equilibrium was not reached. Such an interpretation is fully consistent with the different $D_{\mathrm{SO} 4}$ values recorded at other anion 


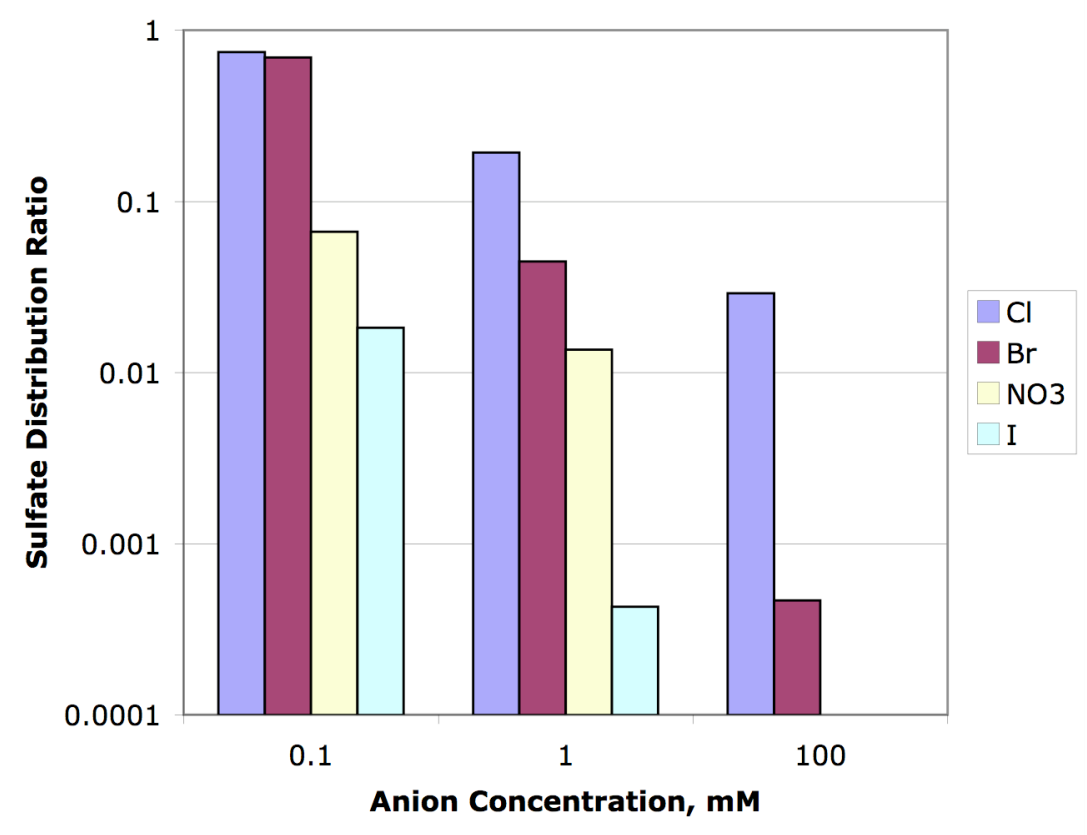

(a)

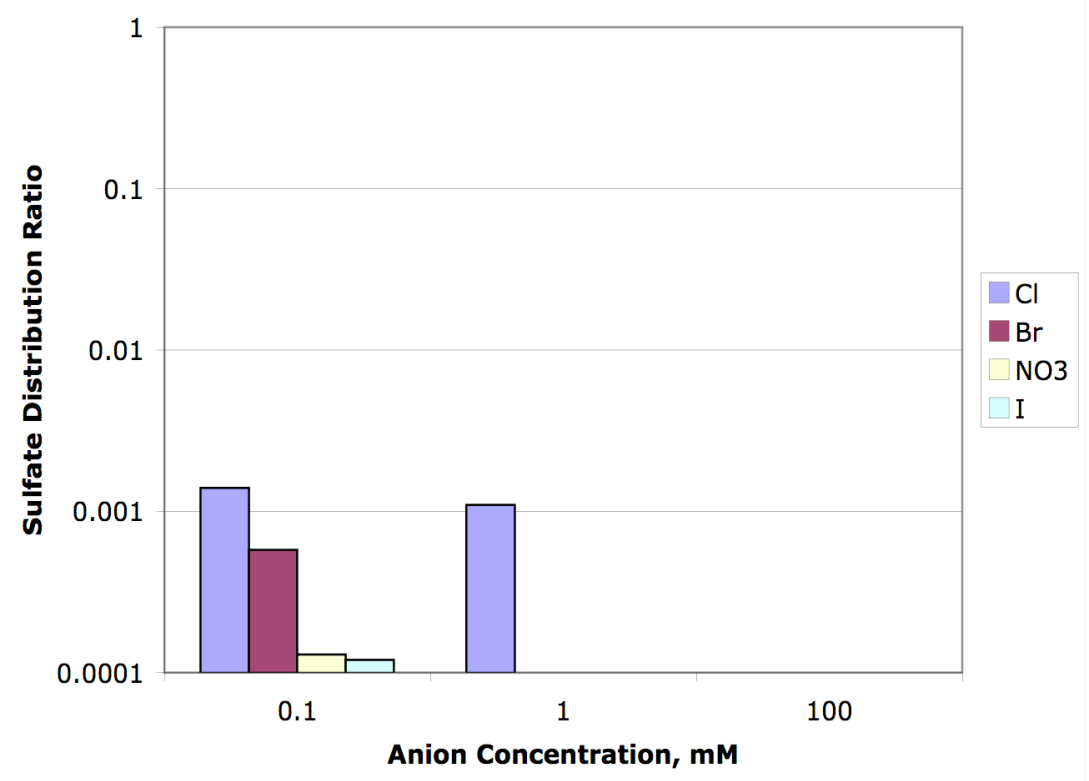

(b)

Figure S1. Attempts at determining the exchange selectivity of $[1 \cdot 2 \mathrm{H}]^{2+} \cdot \mathrm{SO}_{4}{ }^{2-}$ in toluene Organic/Aqueous volume ratio $(\mathrm{O} / \mathrm{A})=1, T=25^{\circ} \mathrm{C}, t=4 \mathrm{hr}$. Aqueous phase: $\left[\mathrm{Na}_{2} \mathrm{SO}_{4}\right]=$ $0.5 \mathrm{mM}$, variable concentration of background anions (sodium salts). (a) Organic phase: $[\mathrm{A} 336 \mathrm{~N}]=0.1 \mathrm{mM},\left[[\mathbf{1} \cdot 2 \mathrm{H}]^{2+} \cdot \mathrm{SO}_{4}{ }^{2-}\right]=0.5 \mathrm{mM}$. (b) Organic phase: $[\mathrm{A} 336 \mathrm{~N}]=0.1 \mathrm{mM}$. 
concentrations. This is likely because the increased concentration of competing anion will decrease the effectiveness of the phase-transfer catalyst. The control experiment (Fig. S1(b)) indeed shows that lower concentrations of sulfate will be associated with the phase-transfer catalyst in the organic phase in the presence of the more highly competitive anions.

\section{Base-Stripping Studies}

Toluene solutions, $0.5 \mathrm{mM}$ in $[\mathbf{1} \cdot 2 \mathrm{H}]^{2+} \cdot \mathrm{SO}_{4}{ }^{2-}$ and $0.1 \mathrm{mM}$ in $\mathrm{A} 336 \mathrm{~N}$, were contacted for $1 \mathrm{~h}$ with $0.1 \mathrm{M}$ aqueous $\mathrm{NaOH}$ using a rotating mixer (1:1 phase volume ratio, $5 \mathrm{~mL}$ of each phase, in $15 \mathrm{~mL}$ conical vials, at $25^{\circ} \mathrm{C}$ ). The resulting samples were centrifuged after removing them from the mixer to separate the phases. The aqueous phases were measured for sulfur content using ICP-AES. The organic phases were restripped with an additional volume of $0.1 \mathrm{mM} \mathrm{NaOH}$ in water under the same conditions. The process was repeated until sulfur measurements of the aqueous phases reached background.

Contacting these final organic phases, which contained $0.1 \mathrm{mM} \mathrm{A336 \textrm {N }}$ and 0.5 $\mathrm{mM}$ [1], with 0.1-1.0 $\mathrm{M} \mathrm{H}_{2} \mathrm{SO}_{4}$, failed to reprotonate the cyclo[8]pyrrole 1, as judged from simple naked-eye colorimetric detection and from the observed failure to reintroduce radioactive sulfate anion back into the organic phase.

\section{Re-acidification Studies}

The substitution of trioctylamine (TOA) for $\mathrm{A} 336 \mathrm{~N}$ in the organic phase and at the same $0.1 \mathrm{mM}$ concentration allowed for both effective base-stripping and reacidification with sulfuric acid. Specifically, toluene solutions, $0.5 \mathrm{mM}$ in $[\mathbf{1} \cdot 2 \mathrm{H}]^{2+} \cdot \mathrm{SO}_{4}{ }^{2-}$ and $0.1 \mathrm{mM}$ in TOA, were contacted for $1 \mathrm{~h}$ with $0.1 \mathrm{M}$ aqueous $\mathrm{NaOH}$ using a rotating mixer $(1: 1$ phase volume ratio, $5 \mathrm{~mL}$ of each phase, in $15 \mathrm{~mL}$ conical vials, at $25^{\circ} \mathrm{C}$ ). The resulting samples were centrifuged after removing from the mixer to separate the phases. The aqueous phases were measured for sulfur content using ICPAES. The resulting free-base toluene solutions, $0.1 \mathrm{mM}$ TOA and $0.5 \mathrm{mM}$ [1], were contacted with 0.1-1.0 $\mathrm{M} \mathrm{H}_{2} \mathrm{SO}_{4}$ solutions using a rotating mixer (1:1 phase volume ratio, $5 \mathrm{~mL}$ of each phase, in $15 \mathrm{~mL}$ conical vials, at $25^{\circ} \mathrm{C}$ ) for several hours in order to 
reprotonate the free-base form of cyclo[8]pyrrole $\mathbf{1}$ to give back $[\mathbf{1} \cdot 2 \mathrm{H}]^{2+} \cdot \mathrm{SO}_{4}{ }^{2-}$. The resulting samples were centrifuged after removing from the mixer to separate the phases. The organic layer, $0.5 \mathrm{mM}$ in $[\mathbf{1} \cdot 2 \mathrm{H}]^{2+} \cdot \mathrm{SO}_{4}{ }^{2-}$ and $0.1 \mathrm{mM}$ in TOA, was stripped again under the same conditions as the first base strip. ICP-AES analysis was consistent within experimental error with identical quantitative removal of sulfate for both the initial and follow up stripping steps, Strip 1 and Strip 2. The cyclo[8]pyrrole, 1, is considered to be stable to both acid and base, as judged from the fact that no net loss in sulfur content is observed, as measured by ICP-AES; this proved true even when the samples of $[1 \cdot 2 \mathrm{H}]^{2+} \cdot \mathrm{SO}_{4}{ }^{2-}$ produced via this process were subject to several additional rounds of stripping and reprotonation. It was found possible to prepare the dichloride salt $[1 \bullet 2 \mathrm{H}]^{2+} \bullet\left(\mathrm{Cl}^{-}\right)_{2}$ in a similar manner, substituting aqueous $\mathrm{HCl}$ solutions for the $\mathrm{H}_{2} \mathrm{SO}_{4}$ solutions. By contrast, the uptake of nitric acid to give the analogous nitrate form $[\mathbf{1} \cdot 2 \mathrm{H}]^{2+} \cdot\left(\mathrm{NO}_{3}{ }^{-}\right)_{2}$ was impractically slow.

\section{Nitrate-Dependence Experiment (Figure 2)}

The dinitrate form of cyclo[8]pyrrole, $[\mathbf{1} \cdot 2 \mathrm{H}]^{2+} \cdot\left(\mathrm{NO}_{3}{ }^{-}\right)_{2}$, was prepared by equilibrating a toluene solution of $0.5 \mathrm{mM}[\mathbf{1} \cdot 2 \mathrm{H}]^{2+} \cdot \mathrm{SO}_{4}{ }^{2-}$ and $0.1 \mathrm{mM}$ TOA with $0.1 \mathrm{M}$ $\mathrm{HNO}_{3}$. The following equilibration conditions were used: $5-10 \mathrm{~mL}$ toluene solution, $t=$ $1-5 \mathrm{~h}, 25^{\circ} \mathrm{C}, \mathrm{O} / \mathrm{A}=1: 2$. Several rounds of equilibration were necessary to effect complete sulfate removal, as determined by ICP-AES. Once $[\mathbf{1} \cdot 2 \mathrm{H}]^{2+} \cdot\left(\mathrm{NO}_{3}^{-}\right)_{2}$ was prepared, it was tested as follows: First, $0.4 \mathrm{~mL}$ of a toluene solution of $0.5 \mathrm{mM}$ $[1 \cdot 2 \mathrm{H}]^{2+} \cdot\left(\mathrm{NO}_{3}\right)_{2}$ and $0.1 \mathrm{mM}$ TOA were added to $2.0 \mathrm{~mL}$ polypropylene centrifuge tubes. The centrifuge tubes containing the organic phases were transferred to a separate hood in a radiological area for addition of the sulfur-35 tracer. A $0.4 \mathrm{~mL}$ aliquot of the spiked $\mathrm{Na}_{2}{ }^{35} \mathrm{SO}_{4}$ tracer solution was added to each centrifuge tube by automatic pipette to give a 1:1 phase volume ratio. The aqueous solution consisted of $0.02 \mathrm{mM} \mathrm{Na}_{2} \mathrm{SO}_{4}$ and $\mathrm{NaNO}_{3}(1000,300,100,30,10,3,1,0.3$, and $0.1 \mathrm{mM})$ spiked with $\mathrm{Na}_{2}{ }^{35} \mathrm{SO}_{4}$. The activity of the aqueous phase prior to equilibration was approximately $1 \mu \mathrm{Ci} / \mathrm{mL}$. These centrifuge tubes were collected into larger, $50 \mathrm{~mL}$ conical vials (approximately 4 tubes per vial) to provide for secondary containment. After checking for radioactive contamination on the surfaces of the vials, the samples were removed from the 
radiological area and were placed on a rotating mixer held within a temperaturecontrolled airbox $\left(t=16 \mathrm{hr}, \mathrm{O} / \mathrm{A}=1,25^{\circ} \mathrm{C}\right)$. Sampling and radiochemical analysis of the two phases were carried out as described above. 